\title{
FRAXF in a patient with chromosome 8 duplication
}

Angela M Vianna-Morgante, Regina C Mingroni-Netto, Ana C C Barbosa, Paulo A Otto, Carla Rosenberg

\begin{abstract}
We report on a folate sensitive fragile site at Xq27-28 in a girl with a multiple congenital anomalies and mental retardation syndrome, who also carries a duplication of the long arm of chromosome 8. The fragile site was shown by FISH to be distal to both FRAXA and FRAXE. DNA hybridisation with probe OxF14 showed the amplification of the CGG repeats of locus FRAXF in the patient and in her clinically normal mother.
\end{abstract}

(F Med Genet 1996;33:611-614)

Key words: FRAXF, dup(8q).

FRAXA, mapping at Xq27.3, is the most frequent fragile site known to have clinical manifestations, namely the fragile $\mathrm{X}$ syndrome. The associated mutation is the result of an amplification of CGG triplet repeats in the FMR1 gene. ${ }^{1-3}$ Since the identification of this mutation, many families ascertained through mental retardation and presenting a fragile site at Xq27-Xq28 have been shown not to have the FMR1 expansion. ${ }^{14}$ Other families have been found with high levels of fragile $\mathrm{X}$ expression in unaffected people of both sexes. ${ }^{56} \mathrm{~A}$ second folate sensitive rare fragile site, FRAXE, was identified in some of these families, lying distal to FRAXA and proximal to DXS296. ${ }^{78}$ It was cloned by Knight $e t a l^{9}$ and was shown to be associated with the expansion of a GCC trinucleotide repeat. More recently, a third rare fragile site, FRAXF, was mapped distally to DXS296 and consequently is distal to both FRAXA and FRAXE. ${ }^{10}$ In 1994, Ritchie et $a l^{11}$ cloned DNA sequences that included this fragile site which involved the expansion of a (GCCGTC)n(GCC)n compound array. Folate sensitivity of this fragile site was not precisely defined.

Here we report on a patient with FRAXF who also had a partial duplication of the long arm of chromosome 8 .

\section{Patient and methods}

CLINICAL DATA

The patient, a girl, is the third child born to healthy, non-consanguineous parents. Her two brothers are phenotypically normal. She was born at term after an uneventful pregnancy. Her neuropsychomotor development was delayed.

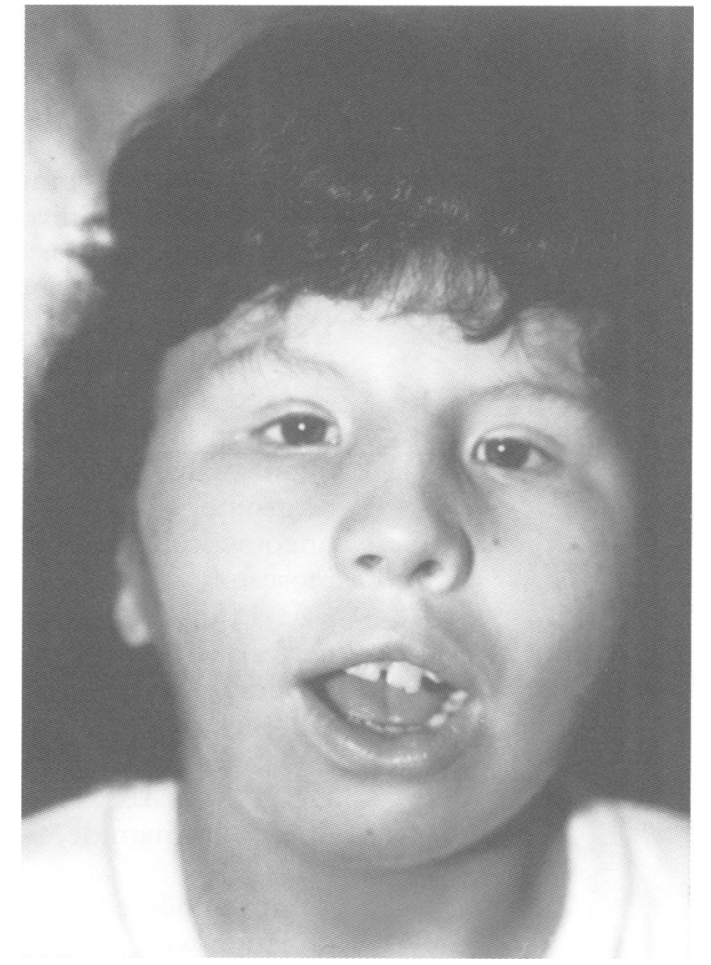

Figure 1 Patient at 8 years of age.

She was examined at 8 years of age (fig 1) and had severe mental retardation. Her height $(125 \mathrm{~cm})$, weight $(30.3 \mathrm{~kg})$, and head circumference $(49.5 \mathrm{~cm})$ were on the $3 \mathrm{rd}$ centile. Her expressionless face was wide and slightly asymmetrical. The forehead was narrow and facial dysmorphism included slight microphthalmia, blepharophimosis, epicanthic folds, apparent telecanthus, a broad nasal root, and a long philtrum. The palate was high arched and the teeth were irregularly implanted. The gingivae were hyperplastic and the upper frenulum was thick. The ears were small, low set, and posteriorly angulated, with abnormal folding of the helices. The neck was short and broad and the posterior hairline was low. The nipples were hypoplastic and widely spaced. General limitation of movement in the joints was present. The hands showed camptodactyly and proximally implanted thumbs. Club feet with overlapping of toes and deep longitudinal plantar furrows were present. Radiological examination of the head and vertebral column confirmed the facial asymmetry and showed marked thoracic scoliosis. No abnormalities were detected by abdominal ultrasound examination. 
CHROMOSOME ANALYSIS AND FRAGILE SITE DETECTION

Chromosome analysis was performed on $G$ banded metaphases from peripheral blood lymphocytes. The folate sensitivity of the fragile site was assessed by culturing the lymphocytes in (1) TC199 with $15 \%$ bovine calf serum, (2) TC199 with $15 \%$ serum and the addition of FUdR at a final concentration of $2 \times 10^{-7} \mathrm{~mol} / 1$ for the last 24 hours, and (3) RPMI 1640 with $15 \%$ serum.

IN SITU HYBRIDISATION AND PROBE DETECTION The identification of the extra material in the rearranged chromosome 8 was performed using a chromosome 8 library (pBS8, kindly supplied by J W Gray, University of California, San Francisco). In order to investigate the fragile site on the $\mathrm{X}$ chromosome, probes VK21A, $1.3 \mathrm{~kb}$, and $\mathrm{VK} 21 \mathrm{C}, 2 \cdot 5 \mathrm{~kb}$, which identify the DXS296 locus distal to FRAXA and FRAXE (a kind gift from G Suthers, The Adelaide Children's Hospital, North Adelaide) were simultaneously hybridised. The $\mathrm{X}$ chromosome centromeric sequence $\mathrm{pBamX} 5^{12}$ allowed the unequivocal identification of the $\mathrm{X}$ chromosomes.

Hybridisation and probe detection were performed as previously described. ${ }^{1314}$ Briefly, probes were biotin labelled by nick translation (Bionick, BRL) and precipitated together with 100 times excess of unlabelled human placental DNA (SIGMA). Hybridisation was performed in $50 \%$ formamide, $2 \times$ SSC for 25 to 35 hours at $37^{\circ} \mathrm{C}$.

Immunodetection was accomplished by incubation with an antibiotin raised in goat, followed by incubation with a rabbit anti-goat IgG conjugated to FITC (both from Vector Laboratories). Slides were counterstained with propidium iodide in antifade solutions. Signals were visualised under a Zeiss Axiophot microscope equipped with a FITC filter and photographed using Ektacrome 400 (Kodak). The colour slides were scanned and converted to black and white prints through image processing (Adobe Photoshop).

SOUTHERN BLOTTING

DNA isolated from peripheral blood lymphocytes was doubly digested with EcoRIEagI for FRAXA analysis, and with HindIII$B s s$ HII for FRAXF analysis. Digests were subjected to electrophoresis in $0.7 \%$ agarose gels and transferred onto nylon membranes following standard methods. The DNA probes StB12.3 (kind gift from F Rousseau, Faculté de Médecine, Strasbourg) and OxF14 (kindly supplied by Kay E Davies, John Radcliffe Hospital, Oxford) were radiolabelled with ${ }^{32} \mathrm{P}$ dATP by random priming (BRL) and hybridised to the filters at $42^{\circ} \mathrm{C}$ in a hybridisation solution containing 50\% formamide and $3 \times$ SSC. The filters were washed to a stringency of $2 \times \mathrm{SSC}$ and exposed to Kodak XOMAT film at $-70^{\circ} \mathrm{C}$.

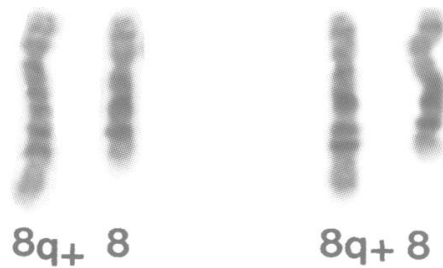

A

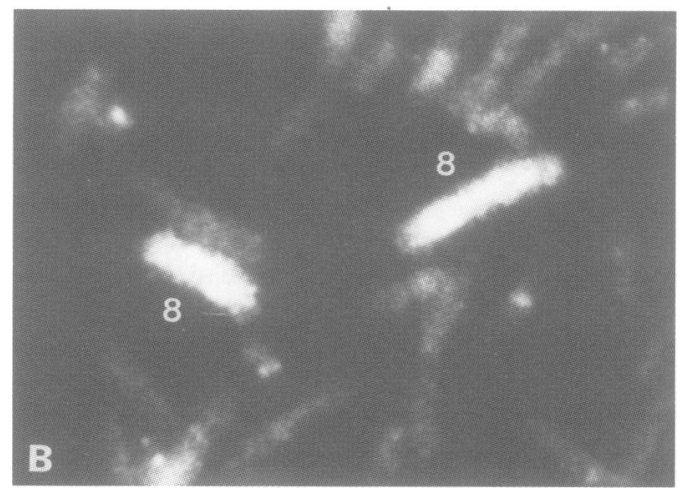

Figure 2 (A) Chromosome 8 with an enlarged long arm after $G$ banding and $(B)$ identification of the additional segment as derived from chromosome 8 by painting with chomosome 8 library ( $p B S 8$ ).

\section{Results}

Cytogenetic analysis after $\mathrm{G}$ banding showed a $46, \mathrm{XX}, 8 \mathrm{q}+$ karyotype in the patient (fig $2 \mathrm{~A}$ ) and normal chromosomes in her parents. FISH with a chromosome 8 library allowed the identification of the extra material as derived from chromosome 8 (fig 2B). Banding patterns were compatible with a complex rearrangement that included the insertion of the segment $8 \mathrm{q} 22.3 \rightarrow \mathrm{q} 24.3$ into band $8 \mathrm{q} 24.1$.

For FISH studies, lymphocytes were cultured, by chance, under conditions for the induction of folate sensitive fragility. A fragile site at $\mathrm{Xq} 27$-q28 (fig 3A) was then observed in

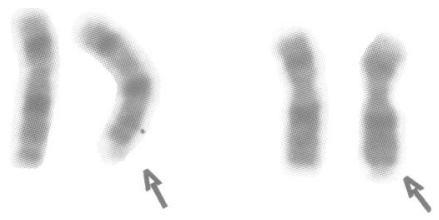

A

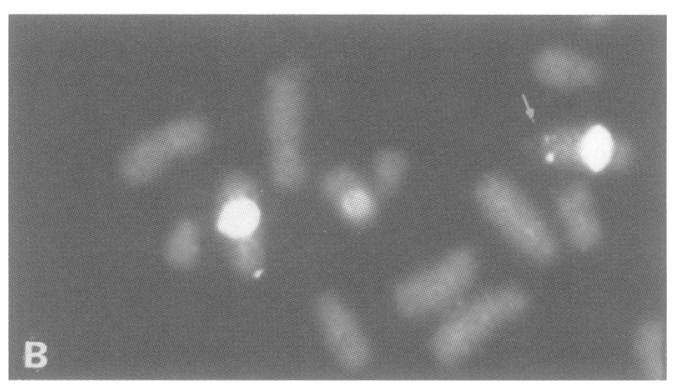

Figure 3 (A) Fragile site at Xq27-28 detected in 40\% of metaphases, after $G$ banding; $(B)$ in situ hybridisation of probes $V K 21 A$ and $V K 21 C$, with the fragile site lying distally to the fluorescence signal. The alphoid sequence pBamX5 identifies the $X$ chromosome centromere. 
Table 1 Frequency of the fragile site expressed by the patient, her mother, and her brother in lymphocytes cultured under conditions that induce folate sensitive fragility or that do not

\begin{tabular}{llll}
\hline Subjects & \multicolumn{2}{l}{ Culture systems } \\
\cline { 2 - 4 } & TC199 & TC199+FUdR & RPMI 1640 \\
\hline Patient & $2 / 43$ & $20 / 50$ & \\
Mother & & $39 / 101$ & $0 / 100$ \\
Brother & & $1 / 200$ & $0 / 100$ \\
\hline
\end{tabular}

20/50 metaphases from a culture to which FUdR had been added, and in $2 / 43$ cells cultured in TC199 without inducing agents. For investigating the sensitivity of the fragile site to folate further a third group of lymphocyte cultures was performed in TC199 with the addition of FUdR, and in RPMI 1640, which contains 100 times more folic acid. The patient's mother and one brother were also examined, but her father was not available at the time. Expression of the fragile site in the patient was observed only in the induced culture. Her mother showed a similar fragile site in 1/200 metaphases from the culture with FUdR. Her brother did not manifest the fragile site in either culture system. A summary of the investigation of the fragile site is shown in table 1 . These results indicate that the fragile site is folate sensitive.

DNA testing for the FMR1 mutation was negative in the patient and her mother. These results led us to investigate the site of the chromosomal fragility by FISH. VK 21 probes, which map distally to FRAXA and FRAXE, were shown to hybridise proximally to the fragile site in our patient, as in the case of FRAXF (fig 3B). Further DNA analysis with probe OxF14 agreed with these results (fig 4). Amplifications of approximately $1000 \mathrm{bp}$ in the patient and $500 \mathrm{bp}$ in her mother were detected. The expanded allele in the patient and her mother appeared to be methylated. However, interpretation of the methylation status in the mother was complicated, because the size of the amplification predicts that the unmethylated segment would migrate together with her normal allele (fig 4, lanes 5 and 6).

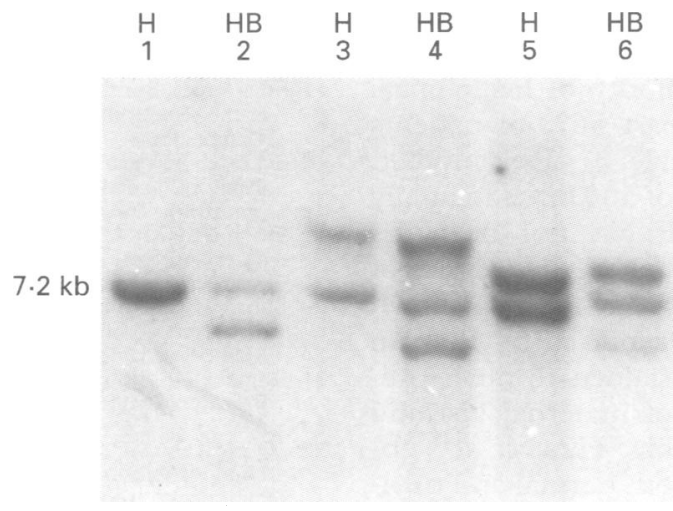

Figure 4 Hybridisation of probe OxF14 after DNA digestion with HindIII $(H)$ and HindIII-BssHII (HB): lanes 1 and 2, normal female control; lanes 3 and 4, patient with an expanded allele $(\Delta=\sim 1000 \mathrm{bp})$, which is resistant to BssHII digestion; lanes 5 and 6, normal mother with an expansion of about 500 bp in an allele which seems to be methylated.
Table 2 Clinical signs observed in at least $50 \%$ of the patients with $8 q$ duplications and in the present case ${ }^{1617}$

\begin{tabular}{|c|c|}
\hline Dup $8 q$ & Present case \\
\hline Developmental delay & + \\
\hline Mental retardation & + \\
\hline Postnatal growth retardation & + \\
\hline Brachycephaly & - \\
\hline Prominent forehead & - \\
\hline Wide face & + \\
\hline Midface hypoplasia & - \\
\hline Hypertelorism/telecanthus & + \\
\hline Abnormal palpebral slant & - \\
\hline Infraorbital creases & - \\
\hline Eye abnormalities & + \\
\hline Broad nasal root & + \\
\hline Depressed nasal bridge & - \\
\hline Anteverted nostrils & - \\
\hline Long philtrum & + \\
\hline Downturned mouth & - \\
\hline Thin upper lip & - \\
\hline Everted lower lip & + \\
\hline Arched/high palate & + \\
\hline Cleft palate/bifid uvula & + \\
\hline Abnormal dentition & + \\
\hline Gingival hyperplasia & + \\
\hline Thick frenulum & + \\
\hline Micrognathia & - \\
\hline Low set ears & + \\
\hline Malformed ears & + \\
\hline Posteriorly angulated ears & + \\
\hline Broad/short neck & + \\
\hline Low posterior hairline & + \\
\hline Pectus excavatum & - \\
\hline Widely spaced nipples & + \\
\hline Camptodactyly & + \\
\hline Clinodactyly & - \\
\hline Overlapping of toes & + \\
\hline Deep plantar/palmar furrows & + \\
\hline Joint contractures & + \\
\hline Hirsutism & + \\
\hline Scoliosis & + \\
\hline Abnormal sternal ossification & ? \\
\hline Absent/small patellae & - \\
\hline Heart defect & - \\
\hline Urinary tract anomalies & - \\
\hline
\end{tabular}

\section{Discussion}

The fragile site in our patient was shown to be distal to FRAXA and FRAXE, lying in the region where FRAXF has been mapped. ${ }^{10}$ Southern analysis confirmed the cytogenetic evidence, since an expansion in the FRAXF locus was detected in the patient and in her mother. Besides the family described by Hirst et $a l,{ }^{10}$ FRAXF was also identified through FISH by Baker et $a l^{15}$ as the fragile site in the family first described by Romain and Chapman. ${ }^{6}$ Richie et $a l^{11}$ cloned sequences of FRAXF in a mentally retarded male from a third family.

Since fragility at this site was expressed in our patient only under low folate conditions, we considered it to be folate sensitive. In the original family reported by Hirst et $a l^{10}$ no fragile site was observed without induction in all but one person who also had the highest expression $(26 \%)$. It was then suggested that FRAXF could be folate insensitive at least in those people manifesting it at high frequencies. Contrary to this, the fragile site in the patient described here was expressed in a higher proportion of cells $(40 \%)$ in two independent cultures and was clearly folate sensitive. However, the fragility observed in the family reported by Romain and Chapman ${ }^{6}$ was manifested without inducing agents in frequencies varying from $5 \%$ to $14 \%$. It is possible that conditions for its expression might depend on individual differences.

The heterozygous mother of our proband expressed the fragile site in only one out of 200 cells. Low frequencies or no expression of 
Table 3 Clinical signs of our patient and their occurrence in patients with $8 q$ duplications

\begin{tabular}{lc}
\hline Our patient & Dup $8 q$ \\
\hline Developmental delay & + \\
Mental retardation & + \\
Postnatal growth retardation & + \\
Narrow forehead & - \\
Asymmetrical face & + \\
Wide face & - \\
Slight microphthalmia & + \\
Apparent telecanthus & $+^{*}$ \\
Blepharophimosis & $+^{*}$ \\
Epicanthic folds & + \\
Broad nasal root & + \\
Long philtrum & + \\
Everted lower lip & + \\
High arched palate & + \\
Irregularly implanted teeth & + \\
Gingival hyperplasia & + \\
Thick upper frenulum & $+^{*}$ \\
Small ears & + \\
Low set ears & + \\
Posteriorly angulated ears & + \\
Malformed ears & + \\
Broad short neck & + \\
Low posterior hairline & + \\
Widely spaced nipples & + \\
Camptodactyly & + \\
Proximally implanted thumbs & + \\
Club feet & + \\
Overlapping toes & + \\
Deep plantar furrows & + \\
Joint contractures & + \\
Hirsutism & + \\
Scoliosis & + \\
\hline + Present in at least 50\% of dup 8q patients. & ${ }^{*}{ }^{*}$ \\
+ Present in dup 8q at lower frequencies. & \\
- Not described in dup 8q. &
\end{tabular}

FRAXF does not seem to be rare. Frequencies of $1 \%$ and $2 \%$ were found by Hirst et al ${ }^{10}$ in an obligate carrier and in a mentally retarded girl, respectively. In the study of Romain and Chapman, ${ }^{6}$ neither parent of two carrier sibs manifested the fragile site. The relationship of the cytological manifestation, size of the amplification, and methylation remains to be clarified. Our patient had a high expression of the fragile site and this was associated both with a large expansion (1000 bp) and methylation. The expansion in her mother was smaller $(500 \mathrm{bp})$, but the methylation status of the mutated allele could not be clearly resolved.

The clinical picture of mental retardation and multiple congenital anomalies in our patient can be explained by the partial duplication of chromosome 8 (presumptively $8 \mathrm{q} 22.3 \rightarrow 8 \mathrm{q} 24.3$ ). She presents $62 \%$ of the clinical features described in at least $50 \%$ of the patients with $8 \mathrm{q}$ duplications which include segments $8 \mathrm{q} 22,8 \mathrm{q} 23$, or $8 \mathrm{q} 24$ to $8 \mathrm{qter}$ (table $2)$. Furthermore, the majority of her clinical signs are present in at least $50 \%$ of patients with $8 \mathrm{q}$ duplications (table 3). Her mother, who carries an expansion of $500 \mathrm{bp}$, is mentally normal. Indeed, FRAXF has not been associated with a clinical phenotype in either of the two other families in which it was shown to segregate. The family reported by Romain and Chapman ${ }^{6}$ was ascertained through prenatal diagnosis because of maternal age and was clinically unremarkable. Hirst et $a l^{10}$ observed the fragile site in both normal and mentally retarded females, but not in one affected girl of the same family. The expanded alleles in the normal mother $(\Delta=\sim 1200 \mathrm{bp})$ and her affected daughter $(\Delta=\sim 1000 \mathrm{bp})$ were methylated. ${ }^{11}$ In the mentally retarded male described by Ritchie et $a l,{ }^{11}$ an amplification of $2000 \mathrm{bp}$ was associated with methylation. These data indicate a lack of association of mental retardation with FRAXF expansion and methylation. A bias of ascertainment through cytogenetic analysis of mentally retarded subjects would explain the number of affected people in whom FRAXF has been described.

The authors are indebted to Ms Ligia S Vieira and Marlice $P$ Robles for technical assistance. This work was supported by FAPESP and CNPq.

1 Oberlé I, Rousseau F, Heitz D, et al. Instability of a 550 bp DNA segment and abnormal methylation in fragile $\mathrm{X}$ syndrome. Science 1991;252:1097-102.

2 Verkerk AJMH, Pieretti M, Sutcliffe JS, et al. Identification of a gene (FMR1) containing a CGG repeat coincident with a breakpoint cluster region exhibiting length variation in fragile X syndrome. Cell 1991;65:905-14.

3 Yu S, Pritchard M, Kremer E, et al. The fragile X genotype characterized by an unstable region of DNA. Science 1991 ; 252:1179-81.

4 Nakahori Y, Knight SJL, Holland J, et al. Molecular heterogeneity of the fragile X syndrome. Nucleic Acids Res 1991 19:4355-9.

5 Voeckel MA, Piquet PN, Pelissier MC, et al. Study of a family with a fragile site of the $\mathrm{X}$ chromosome at Xq27 28 without mental retardation. Hum Genet 1989;81:353-7.

6 Romain DR, Chapman CJ. Fragile site Xq27.3 in a family without mental retardation. Clin Genet 1992;41:33-5.

7 Sutherland GR, Baker E. Characterization of a new fragile site easily confused with the fragile X. Hum Mol Genet 1992;1:111-3.

8 Flynn GA, Hirst MC, Knight SJL, et al. Identification of the FRAXE fragile site in two families ascertained for $\mathrm{X}$ linked mental retardation. $¥$ Med Genet 1993;30:97-100.

9 Knight SJL, Flannery AV, Hirst MC, et al. Trinucleotide repeat amplification and hypermethylation of a $\mathrm{CpG}$ island repeat amplification and hypermethylation of a CpG islanct

10 Hirst MC, Barnicoat A, Flynn G, et al. The identification of a third fragile site, FRAXF, in Xq27-q28 distal to both
. of a third fragile site, FRAXF, in Xq27-q28 distal to both
FRAXA and FRAXE. Hum Mol Genet 1993;2:197-200.

11 Ritchie RJ, Knight SJL, Hirst MC, et al. The cloning of FRAXF: trinucleotide repeat expansion and methylation at a third fragile site in distal Xqter. Hum Mol Genet 1994; 3:2115-21.

12 Waye JS, Willard HF. Nucleotide sequence heterogeneity of alpha satellite repetitive DNA: a survey of alphoid sequences from different chromosomes. Nucleic Acids Res 1987;15:7549-69.

13 Viegas-Péquignot $\mathrm{E}$, Jeanpierre $\mathrm{M}$, Dutrillaux AM, et al. Detection of 1q polysomy in interphase nuclei of human solid tumours with a biotinylated probe. Hum Genet 1989; 81:311-4.

14 Rosenberg $C$, Janson $M$, Nordeskjöld $M$, Børrensen AL, Vianna-Morgante AM. Intragenic reorganization of RB1 in a complex $(4 ; 13)$ rearrangement demonstrated by FISH a complex $(4 ; 13)$ rearrangement dem Cell Genet 1993;65:268-71.

15 Baker E, Sutherland G, Gedeon A, et al. FRAXA, FRAXE or FRAXF? 6th International Workshop on the Fragile $X$ and X-linked Mental Retardation, 1993, Abstracts:A4

16 Walker AP, Bocian M. Partial duplication 8q12 $\rightarrow \mathrm{q} 21.2$ in two sibs with maternally derived insertional and reciprocal translocations: case reports and review of partial duplications of chromosome 8. Am $\mathcal{F}$ Med Genet 1987;27: 3-22.

17 Sujansky E, Smith ACM, Prescott KE, et al. Natural history of the recombinant (8) syndrome. Am f Med Genet 1993; 47:512-25.

18 Schinzel A. Partial trisomy $8 \mathrm{q}$ in half-sisters with distinct dysmorphic patterns not similar to the trisomy 8 mosaicism syndrome. Hum Genet 1977;37:17-26.

19 Fineman RM, Ablow RC, Breg WR, et al. Complete and partial trisomy of different segments of chromosome 8 : partial trisomy of different segments of chromosom

20 Barnes ICS, Kumar D, Bell RIM. A child with a recombinant of chromosome 8 inherited from her carrier mothers. $\mathcal{f}$ Med Genet 1985;22:67-70.

21 Romain DR, Bloxham RA, Columbano-Green LM, et al. Familial distal trisomy 8 (q24.13 $\rightarrow$ qter). $\mathcal{F}$ Med Genet 1989 ; 26:133-8.

22 Qumsiyeh MB, Wilroy RS, Peeden JN, Tharapel AT. High resolution replication banding combined with in situ hybridization for the delineation of a subtle chromosome rearrangement. Am $\mathcal{F}$ Med Genet 1991;41:99-101. 